\title{
Cryotreated Intrahypothalamic Transplants of Neural Lobe, Sciatic Nerve or Optic Nerve Do Not Support Neurosecretory Axon Regeneration
}

\author{
H. Dieter Dellmann and Jeanine Carithers \\ Department of Veterinary Anatomy and Neuroscience Program, \\ Iowa State University, Ames, IA 50011, USA
}

When the hypothalamo-neurohypophysial tract is transected in the hypothalamus, very limited neurosecretory axon regeneration occurs. However, the proximal stumps of the severed axons regenerate more abundantly when they are exposed to a suitable microenvironment provided by transplanted tissue. Regeneration is most profuse into transplants of freshly collected neural lobe $/ 1 /$, less vigorous into those of sciatic nerve $/ 2 /$, and least pronounced into those of optic nerve $/ 3 /$. Neurosecretory axons also regenerate into neural lobe explants /4/. After 30 days in vitro, neurosecretory axons have been phagocytosed completely, so explants consist primarily of pituicytes 15/. In each type of transplant, regenerated neurosecretory axons form perivascular terminals on pre-existing or new microvessels. Axons are always in close contact with the specific glial cells of each type of transplant, i.e., pituicytes in the neural lobe, neurolemmocytes (Schwann cells) in the sciatic nerve, and astrocytes in the optic nerve.

In order to assess whether or not glial cells of these transplants play an essential role in the regeneration process, we killed these cells by cryotreatment. Neural lobe explants (after 30 days in culture), and pieces of intact sciatic and optic nerves were subjected to three freeze-thaw cycles prior to transplantation into the hypothalamo-neurohypophysial tract transected at the lateral retrochiasmatic area. Animals were killed 15 days later and $50 \mu \mathrm{m}$ thick sections were processed for neurophysin immunohistochemistry and electron microscopy.

Cryotreated transplants of explanted neural lobe were characterized by fibrocytes, abundant extracellular matrix containing many basal lamina remnants, the scarcity of both fenestrated and continuous capillaries, and the absence of pituicytes. Neurosecretory axons did not regenerate into cryotreated neural lobe explants.

Cryotreated sciatic nerve transplants likewise did not support neurosecretory axon regeneration. Neurolemmocytes had disappeared, and the remaining basal lamina tubes were surrounded by a copious extracellular matrix vascularized by continuous and fenestrated capillaries. Fibrocytes and a few macrophages containing phagolysosomes were scattered throughout the transplants.

The microenvironment of cryotreated optic nerve transplants also failed to promote neurosecretory axon regeneration. Astrocytes and oligodendroglial cells were no longer identifiable and macrophages predominated in these transplants. The intercellular space was occupied by fibrocytes and relatively scarce extracellular matrix. Both continuous and a few fenestrated capillaries were present.

In all types of cryotreated transplants, occasional regenerating neurosecretory axons accompanied by basal lamina-surrounded astrocytic processes from the host invaded the periphery of the transplanted tissue, but these did not grow beyond their investment of host glia, nor did they form terminals.

Our experiments support the notion that glial cells are indispensable for neurosecretory axon regeneration, and that the extracellular matrix alone, including basal lamina elements, provides an insufficiently supportive microenvironment.

Supported in part by NSF BNS 8919729 


\section{REFERENCES}

1. Dellmann H-D, Lue L-F, Bellin SI. Neurosecretory axon regeneration into intrahypothalamic neural lobe allografts:neurophysin immunohistochemistry and fine structure. Exp Brain Res 1987; 67: 543-555.

2. Dellmann H-D, Lue L-F, Bellin SI. Peptidergic neurosecretory axons regenerate into sciatic nerve autografts in the rat hypothalamus. Neuroendocrinology 1986; 44: 292-298.

3. Dellman H-D, Lue L-F, Bellin SI, Ouassat M. Magno- cellular neurosecretory axon regeneration into rat intrahypothalamic optic nerve allografts. J Neurosci Res 1989; 24: 163-168.

4. Carithers J, Dellmann H-D. Regeneration of neural lobe-like neurovascular contact regions in explanted neural lobes placed in the hypothalamo-neurohypophysial tract in the lateral retrochiasmatic area. Brain Res, in press.

5. Dellmann H-D, Gabrion J, Privat A. Fine structural changes in explants of the neural lobe of the rat hypophysis. J Neuroendocrinol 1991; 3: 339-347. 

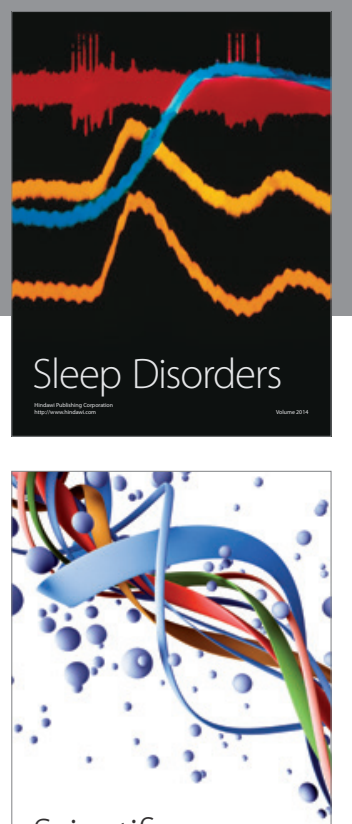

Scientifica
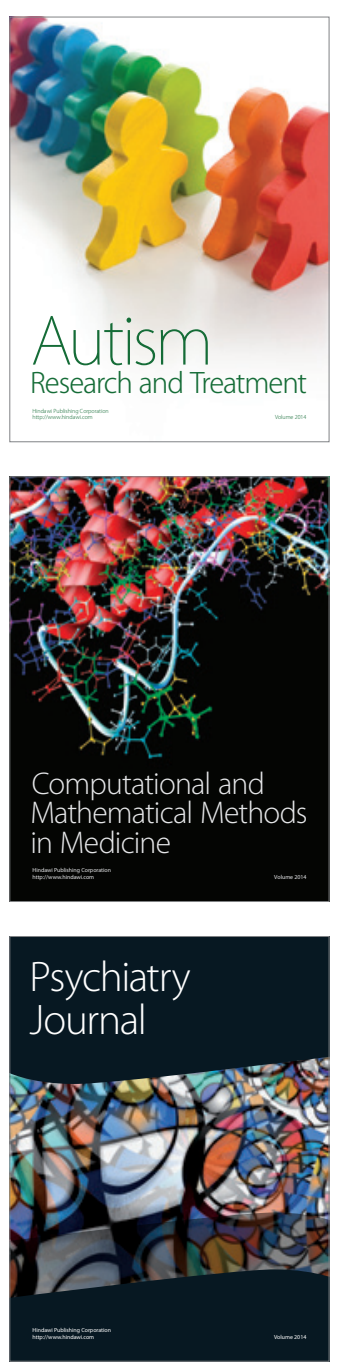
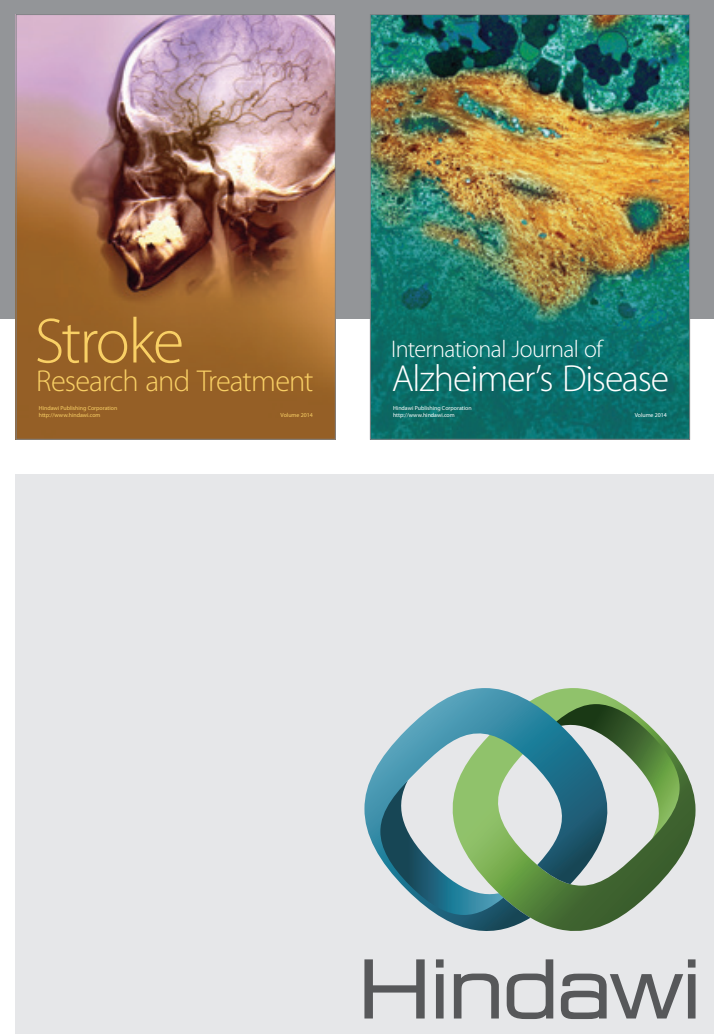

Submit your manuscripts at

http://www.hindawi.com
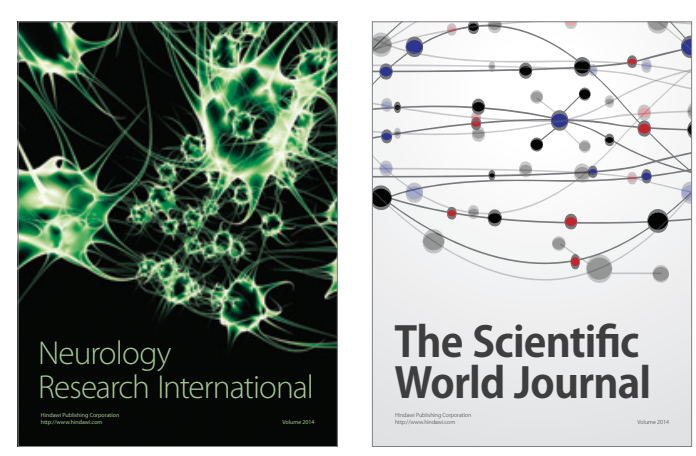

The Scientific World Journal

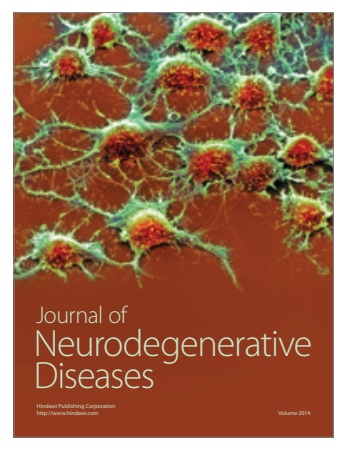

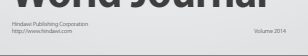

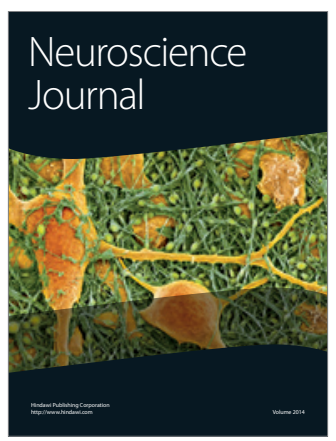

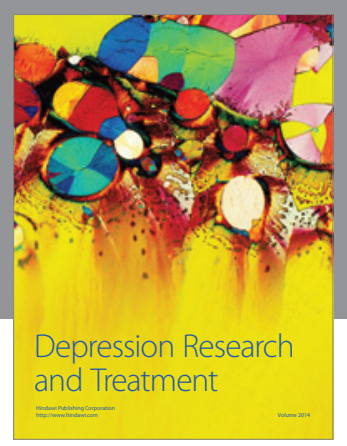
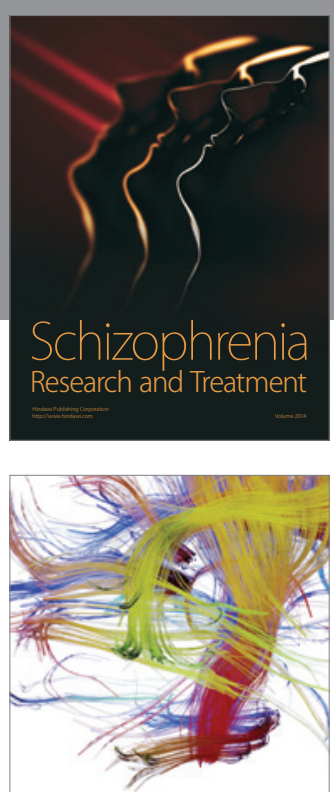

Brain Science

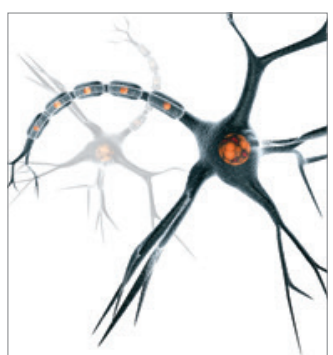

Neural Plasticity
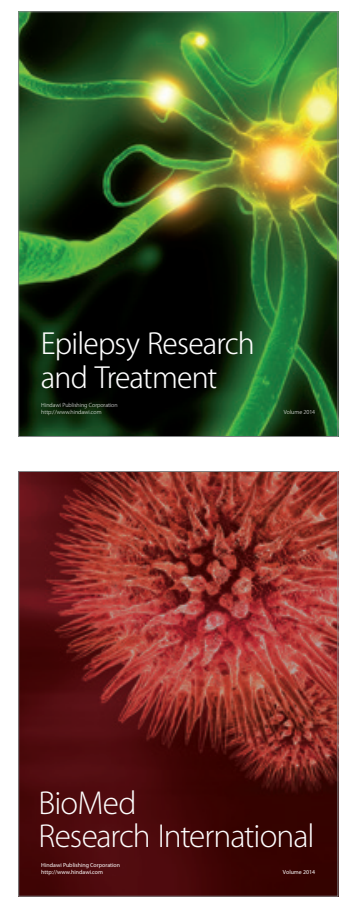

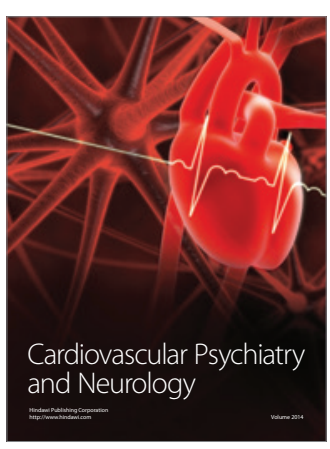

Parkinson's

Disease
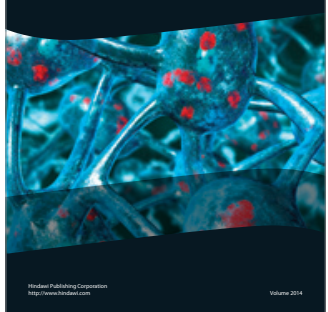